\title{
Erratum to: Genome-wide Analysis of Zinc Transporter Genes of Maize (Zea mays)
}

\author{
Tapan Kumar Mondal • Showkat Ahmad Ganie • \\ Mukesh Kumar Rana • Tilak Raj Sharma
}

Published online: 28 February 2014

(C) Springer Science+Business Media New York 2014

\section{Erratum to: Plant Mol Biol Rep (2014) 32:605-616 \\ DOI 10.1007/s11105-013-0664-2}

In Figure 1 of this article, the chromosome numbers were wrongly indicated as XI (11) and XII (12). These should be IX (9) and X (10) as Maize has only 10 chromosomes. The authors thereby making this note to correct Fig. 1 as shown.

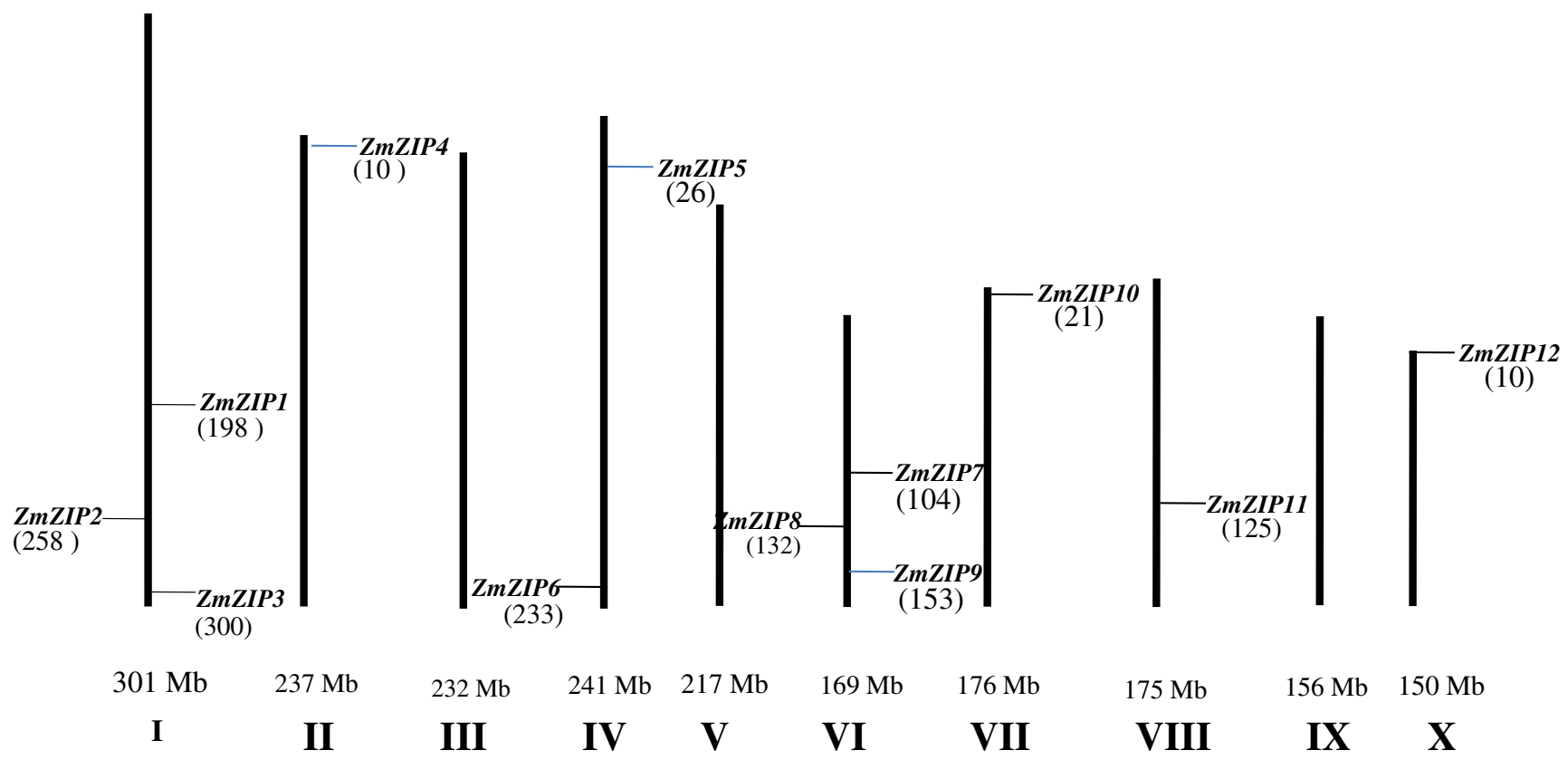

Fig. 1 Locations of the different $Z m Z I P$ genes in the maize genome. Roman number indicated different chromosomes of maize and figure in parentheses indicate the position of the gene in $\mathrm{Mb}$

The online version of the original article can be found at http://dx.doi.org/ 10.1007/s11105-013-0664-2.

T. K. Mondal $(\bowtie) \cdot$ S. A. Ganie $\cdot$ M. K. Rana

Division of Genomic Resource, National Bureau of Plant Genetic

Resource, IARI, Pusa Campus, New Delhi 110012, India

e-mail: mondaltk@yahoo.com

\section{T. R. Sharma}

National Research Centre on Plant Biotechnology, IARI,

Pusa Campus, New Delhi 110012, India 